\title{
OS REFLEXOS DA CRISE FINANCEIRA NAS PRÁTICAS DE RESPONSABILIDADE SOCIAL DE EMPRESAS DOSETOR DE ENERGIA ELÉTRICA QUE COMPÕEM O ÍNDICE DE SUSTENTABILIDADE EMPRESARIAL DABM\&F-BOVESPA
}

THE CONSEQUENCES OF THE FINANCIAL CRISIS IN THE PRACTICAL ONES OF SOCIAL RESPONSIBILITY OFTHE COMPANIES OF THE SECTOR OF ELECTRIC ENERGY THAT COMPOSE THE ÍNDICE DESUSTENTABILIDADE EMPRESARIAL (ISE) BM\&F- BOVESPA

\section{Breno de Paula Andrade Cruz \\ Darla Renata Conceição de Assis}

\section{RESUMO}

O presente artigo tem como objetivo identificar os reflexos da crise financeira nas práticas de Responsabilidade Social das empresas do setor de Energia Elétrica que compõem o Índice de Sustentabilidade Empresarial (ISE) BM\&F-Bovespa. Como um trabalho exploratório, numa perspectiva qualitativa, foram selecionadas quatro empresas do referido setor e entrevistados 04 executivos responsáveis pela área de Responsabilidade Social. A técnica de coleta de dados foi entrevista por telefone e o método de análise dos dados foi a Análise de Conteúdo. Os resultados da pesquisa apontam que as principais práticas neste setor estão relacionadas ao core business e à preocupação com o público interno. Além disso, tal segmento não sofreu impactos negativos nas práticas de Responsabilidade Social. Talvez isso seja explicado pelo fato das empresas terem tais práticas como pontos centrais em suas políticas e estratégia ou pelo fato deste segmento se encontrar no final da cadeia produtiva.

Palavras-Chave: Crise financeira. Práticas de responsabilidade social. Setor de energia elétrica.

\begin{abstract}
The present article has as objective to identify the consequences of the financial crisis in the practical ones of Social Responsibility of the companies of the sector of Electric Energy that compose the Índice de Sustentabilidade Empresarial (ISE) BM\&F-Bovespa. As a exploratory work, in a qualitative perspective, four companies of the related sector had been selected and interviewed 04 responsible executives for the area of Social Responsibility. The technique of collection of data was interview for telephone and the method of analysis of the data was the Analysis of Content. The results of the research point that main the practical ones in this sector are related to Core business and to the concern with the internal public. Moreover, such segment did not suffer negative impacts in the practical ones from Social Responsibility. Perhaps this is explained by the fact of the companies to have such practical as points central offices in its politics and strategy or by the fact of this segment if to find in the end of the productive chain.
\end{abstract}

Key-Words: Financial crisis. Pratical ones of social responsibility. Sector of electric energy. 


\section{CRISE ECONÔMICA, ESTRATÉGIA E RESPONSABILIDADE SOCIAL}

Alguns temas são evidentes nos debates acadêmicos em Estratégia atualmente. A Responsabilidade Social, seja numa perspectiva teórica ou gerencial, tem se reservado não somente a discutir posicionamentos epistemológicos ou metodológicos, mas, também, os desdobramentos em situações específicas nas organizações brasileiras. Ao mesmo tempo, a Crise Financeira Americana, com reflexos mundiais em diferentes segmentos, também tem sido alvo de calorosas discussões nas Ciências Sociais Aplicadas, bem como, e, principalmente, na Economia. A amplitude deste fenômeno permite discutir e relacionar estes dois temas no XX Enangrad e suas implicações nas áreas de Estratégia em Organizações, Ensino em Administração e Finanças, por exemplo.

É visível o impacto da crise em muitas empresas. Foram diversas as companhias que tiveram que demitir seus funcionários ou dar férias coletivas para que pudessem parar a produção de seus bens manufaturados. Os principais segmentos atingidos foram o de automóveis e o das instituições financeiras. Compreender qual o impacto real desta crise nas organizações, especialmente na análise das práticas de Responsabilidade Social, se torna um componente estimulante para a pesquisa e a prática gerencial em organizações brasileiras.

As bases epistemológicas da Estratégia estiveram apoiadas inicialmente na dimensão econômica da empresa. Uma das primeiras teorias da Estratégia, a Curva de Aprendizado, apresenta esta relação entre Economia e Estratégia ao propor explicar a relação dos custos com a produção e os desdobramentos para a Estratégia (GHEMAWAT, 2002). Willianson (1991) destaca que a eficiência da empresa está condicionada aos princípios de minimização de custos. Estes dois autores, em seus respectivos textos, evidenciam na construção do campo da Estratégia a presença dos conhecimentos em Economia na formação do campo.

Neste sentido, entender a crise financeira, bem como seus reflexos nas práticas de Responsabilidade Social, pode contribuir para o desenvolvimento do campo da Estratégia, sendo que ao abordar a crise financeira se adota uma posição mais clássica (desempenho e estratégia). Por outro lado, ao abordar um posicionamento socialmente responsável de uma empresa, se adota uma postura menos clássica e que vai (indiretamente) de encontro à Teoria das Capacidades Dinâmicas e da Resource-Based View - RBV (reputação como recurso intangível).

O pressuposto deste trabalho é de que aconteceram diversas mudanças nas estruturas de empresas devido à crise que afetou diversos segmentos na indústria e nas atividades de serviços. Além disso, alguns reflexos negativos nas práticas de Responsabilidade Social por empresas brasileiras também podem ter acontecido a partir do início da crise.

Assim, é necessário delimitar conceitualmente os termos Responsabilidade Social Empresarial (RSE) e Práticas de Responsabilidade Social. A abordagem da RSE neste artigo está apoiada na definição de Scott (2007), que sustenta a idéia de que a RSE pode ser entendida como a atuação de uma organização buscando uma postura ética nas perspectivas social e ambiental. Nesta postura consideram-se cinco pilares: (i) sociedade e comunidade; (ii) promoção da cidadania e democracia; (iii) redução das diferenças econômicas entre ricos e pobres; (iv) condições de trabalho e direitos trabalhistas; e (v) comportamento ético. As Práticas de Responsabilidade Social serão, automaticamente, todos os processos, práticas, pressupostos e ideologias que poderão compor uma postura socialmente responsável de uma empresa. 
Um dos mecanismos utilizados no Brasil para mensurar o desempenho e ordenar empresas socialmente responsáveis é o Índice de Sustentabilidade Empresarial BM\&F-Bovespa (ISE). 0 ISE é uma Carteira de Investimentos composto atualmente por 28 empresas que são eleitas anualmente pela BM\&F-Bovespa por terem práticas de gestão sustentáveis e socialmente responsáveis.

Neste sentido, o problema de pesquisa deste estudo é: ocorreram reflexos negativos da crise financeira nas práticas de Responsabilidade Social das empresas do setor de energia elétrica que compõem o Índice de Sustentabilidade Empresarial BM\&F-Bovespa? Os objetivos específicos são: (i) analisar o que são práticas socialmente responsáveis para os gestores das empresas; (ii) verificar se houve reflexos negativos nas práticas de Responsabilidade Social a partir da crise; e, (iii) identificar quais as práticas gerenciais e estratégicas adotadas neste momento que diz respeito à RSE.

Entende-se que o presente estudo é relevante pelo fato de buscar compreender a dinâmica empresarial no que diz respeito à Responsabilidade Social no momento de uma crise econômica que tem desdobramentos não só econômicos, mas também gerenciais e sociais.

Além disso, a interação entre situações/teorias tão debatidas recentemente no âmbito empresarial e acadêmico (RSE e Crise Financeira) contribui para que novas indagações possam emergir deste debate. Ao mesmo tempo, o trabalho contribui significativamente para o campo da Estratégia, uma vez que são exploradas as mudanças recentes que aconteceram a partir de uma crise econômica global e como isso pôde influenciar o posicionamento, a estrutura e as estratégias das empresas, além de apresentar resultados empíricos em uma lacuna de conhecimento (Crise, Estratégia e RSE).

\section{ESTRATÉGIA E RESPONSABILIDADE SOCIAL}

É normal que as empresas busquem resultados satisfatórios e que sempre melhorem seus desempenhos no mercado. Isso não é um fenômeno recente e vem desde a sistematização da Administração com Taylor ou com os primeiros estudos em Estratégia - Matriz Swot, Curva de Aprendizado, Economia de Custos de Transação, Resource-Based View of the Firm, Teoria da Agência, dentre outras (GHEMAWAT, 2002; WILLIANSON, 1991; RUMELT et all 1991). Inicialmente numa perspectiva da firma, os pesquisadores do campo da Estratégia se preocuparam em entender como a estrutura interna (especialmente o produto) poderia tornar a empresa mais competitiva. Foi a McKinsey Company, em 1952, por meio da apresentação dos conceitos de Vantagem Competitiva e Atratividade da Indústria, que começou a direcionar a necessidade de entendimento do ambiente externo (GHEMAWAT, 2002). Porter (1979), em uma perspectiva econômica, consolidou a importância da análise do ambiente externo por meio das forças competitivas em uma indústria.

Em uma abordagem organizacional, em que se foca a análise mais profunda do microambiente, a Teoria das Capacidades Dinâmicas analisa como os recursos e os métodos podem criar e capturar rápidas mudanças propostas pelo ambiente externo. Nesta lógica, a vantagem competitiva é obtida por meio da heterogeneidade dos processos ou pela estrutura das firmas (TEECE et al, 1997). Para os autores, seis atributos são essenciais: fatores de produção, recursos, rotinas e competências organizacionais, competências centrais, produtos e capacidades dinâmicas (habilidade de construir e reconfigurar suas competências a partir do ambiente externo e interno). 
Quando Teece et al (1999) analisaram os processos e a posição das empresas na construção da Vantagem Competitiva na Teoria das Capacidades Dinâmicas, os autores identificaram além de atributos relacionados aos processos internos (processos gerenciais, integração, reconfiguração e transformação) um atributo que antes não fora analisado por outros autores no desempenho das firmas: a Reputação. Para os autores, tal recurso é intangível e pode influenciar o posicionamento da firma no mercado. É nesta perspectiva, que pode-se aprofundar a Reputação como fonte de Vantagem Competitiva.

Em geral, é a busca de uma boa reputação que incentiva muitas empresas a adotarem uma postura socialmente responsável. A competitividade entre os concorrentes e as diversas forças do mercado contribui para a busca constante da excelência. Assim, uma postura estratégica é sempre planejada e executada por diversas organizações. Muitas destas ações estratégicas de grandes empresas recentemente têm o foco na Responsabilidade Social e seus desdobramentos na Imagem e Reputação da empresa. Assim, a reputação passa ser uma variável importante da busca da Vantagem Competitiva. É também geralmente nesta lógica que as empresas adotam uma postura socialmente responsável, uma vez que vêem na reputação uma forma de melhorar o seu desempenho.

A Responsabilidade Social Empresarial pode ser caracterizada como um conjunto de ações amplas, envolvendo os stakeholders de uma empresa, indo além da preservação da imagem da organização na busca por competitividade no cenário econômico. Nesta abordagem deve-se considerar a sociedade, o governo, clientes, fornecedores, público interno, meio ambiente e todos os grupos que podem estar ligados direta ou indiretamente ao cotidiano de uma empresa (BHATTACHARYYA et al, 2008; SCOTT, 2007; HESLIN e UCHOA, 2008; PETERS, 1997).

Buscando atuar nesta perspectiva, uma organização pode considerar seus Acionistas, Governo, Fornecedores, Públicos Interno e Externo, Consumidores, Sociedade, Meio Ambiente, Valores Éticos e Morais. De acordo com Bhattacharyya et al (2008), a RSE deve resgatar a dinâmica do relacionamento entre a sociedade e os negócios da empresa (DAVIS ET all, 1998 apud BHATTACHARYYA et al, 2008, p. 266). Em resumo, em uma empresa, esta estratégia quando adotada, deve estabelecer uma relação de ganhos para a empresa e para a sociedade, por meio da busca contínua de sustentabilidade para estes dois grupos ao longo do tempo. Neste sentido, entender o Comportamento Ético das Empresas é essencial na abordagem da RSE.

Mujih (2007) corrobora para uma perspectiva diferente do debate sobre a responsabilidade social. Para o autor, a RSE pode se apresentar por meio de dois modelos na busca da sobrevivência da empresa. Estes modelos são os de punição e de conformidade. No que diz respeito ao modelo de punição, Mujih destaca que existem fortes penalidades legais para empresas que violam algumas regras. Já no modelo de conformidade, o autor destaca a ênfase dada na relação estabelecida entre a empresa e os agentes reguladores. Peters (1997) vai além ao afirmar que a RSE pode ser entendida como uma estratégia para lidar com o ambiente externo e minimizar uma imagem irresponsável.

É fato que atitudes responsáveis por parte das empresas pode incrementar as vendas de produtos ou serviços e abrir novos mercados (HESLIN e UCHOA, 2008). 0 engajamento de uma empresa em questões ambientais e sociais contribui também para o posicionamento da empresa em um determinado nicho e também no posicionamento de sua marca. Este engajamento, em muitos casos, confunde-se com o assistencialismo a partir do momento que se busca consolidar uma imagem ou reputação diante dos interessados. Uma postura 
socialmente responsável em muitos casos é confundida com práticas assistencialistas ou filantrópicas. Ao buscar um compromisso com a sociedade, especificamente com stakeholders que exercem algum tipo de pressão que pode ser negativa para uma empresa, algumas empresas atuam de forma assistencialista ou filantrópica.

\section{PRÁTICAS DE RESPONSABILIDADE SOCIAL}

Talvez haja uma relação muito tênue entre a percepção filantrópica e assistencialista de RSE para gestores de empresas brasileiras e suas práticas de RSE. Muitas dessas práticas podem estar ligadas a projetos sociais que as empresas mantêm em regiões ou grupos que sofram algum tipo de impacto de atividades principais de uma empresa. A postura teórica adotada neste trabalho vai além, ao dissociar este viés da prática (no Brasil) e não considerar o filantropismo/assistencialismo como RSE, enfocando os diversos stakeholders que podem participar do processo. Como prática de RSE entende-se, neste artigo, como o conjunto de ações deliberadas de uma empresa que busca atender aos interesses dos stakeholders envolvidos no processo.

É necessário diferenciar Práticas Sociais Sustentáveis de Assistencialismo e Filantropismo. É fato que a Responsabilidade Social surge a partir do Filantropismo no século XX com o questionamento entre a geração de lucros e as ações sociais (TENÓRIO, 2004), entretanto, hoje se entende que uma atitude socialmente responsável vai além de práticas assistenciais e filantrópicas.

A sociedade de uma forma geral tem se mobilizado para atender as carências das populações com carências (BARBOSA, 2007). O Filantropismo é entendido como a prática de fazer o bem a um determinado grupo (geralmente está associada a uma caridade). A principal característica da filantropia é a ação estratégica, uma vez que tem a publicidade como pano de fundo. De acordo com Duprat (1993) apud Sanglard (2003), uma ação filantrópica é estratégica porque provoca a visibilidade de uma ação realizada por um grupo e acirra a concorrência entre os agentes que realizaram a ação. Este posicionamento é adotado a partir de Scott (2007) e Bhattacharyya et al (2008), que demarcam a teoricamente a SER numa perspectiva sistêmica envolvendo diversos atores e sociedade.

Neste sentido, tais práticas não podem ser assistencialistas ou filantrópicas. Elas devem ser sustentáveis, promovendo o bem-estar dos públicos interno e externo (SCOTT, 2007), sem perder de vista a visão do negócio (BHATTACHARYYA et al, 2008). Ao se analisar o público interno, os funcionários e as dinâmicas internas são considerados, bem como as políticas de remuneração e de jornada de trabalho, as condições de trabalho, dentre outras características, por exemplo. São estas práticas sistêmicas que consolidam a RSE; tais consideram todos os públicos.

\section{O ÍNDICE DE SUSTENTABILIDADE EMPRESARIAL BM\&F-BOVESPA ${ }^{1}$}

Nos Estados Unidos o investimento em empresas socialmente responsáveis vem crescendo a cada ano. De 1995 a 2007 esse crescimento foi mais de 320\%, e no final desta data os fundos em empresas desse segmento já atingiam US\$ 2,7 trilhões, o que representou 10,76\% das aplicações na indústria de fundos. Atendendo às expectativas de acionistas e seguindo um modismo, foi criado um índice (Índice de Sustentabilidade Empresarial), que tem como objetivo refletir o retorno de uma carteira composta por ações de empresas com reconhecido comprometimento com a responsabilidade social e a sustentabilidade empresarial, e atuar como promotor das boas práticas no meio empresarial brasileiro. Tem-se um Conselho 
Deliberativo, que é presidido pela Bovespa e que tem como parceiros instituições como o Instituto Ethos e o Ministério do Meio Ambiente. A estas instituições cabem as funções de desenvolver o critério de avaliação, enviar questionários, calcular o índice e, por fim, definir e aprovar as empresas selecionadas.

Para avaliar o desempenho das empresas listadas no Bovespa em relação ao aspecto de sustentabilidade, o Conselho achou melhor contratar o Centro de Estudos de Sustentabilidade da Fundação Getúlio Vargas (CES-FGV), devido à sua credibilidade e autoridade no assunto. 0 CES-FGV desenvolveu um questionário para medir o desempenho das empresas emissoras das 150 ações mais negociadas da Bovespa. Este questionário envolve a avaliação de elementos ambientais, sociais e econômico-financeiros de forma integrada, chamados de "triple bottom line".

Paralelo a isso, os questionários contêm outros grupos de indicadores, que por sua vez apresentam critérios gerais (se a empresa publica seus balanços sociais), critérios de natureza do produto (se o produto da empresa traz danos e riscos à saúde dos consumidores), e critérios de governança corporativa. 0 preenchimento do questionário é facultativo, o que demonstra o comprometimento da empresa com as questões de sustentabilidade consideradas cada vez mais importantes pelos investidores e sociedade como um todo.

A carteira final do ISE é composta por um grupo oficial de no máximo 40 empresas que, por sua vez, terão revisão anual. A participação de cada empresa na carteira teórica não pode ultrapassar $25 \%$ do total da carteira. Companhias que estejam sob regime de recuperação judicial, processo falimentar, situação especial, ou ainda que tenham sofrido ou estejam sob prolongado período de suspensão de negociação não integram o ISE.

\section{ENTENDENDO A CRISE ECONÔMICA}

Em um mercado financeiro os números de agentes pessimistas e otimistas tendem a ser equivalentes, gerando a especulação. São estes agentes que definem o valor dos ativos através das operações de oferta e demanda. Quando as expectativas futuras são demasiadamente otimistas, ou seja, atribui-se um valor maior do que realmente se tem, os ativos tendem a supervalorizar-se, o que gera um valor acima daquele valor real de mercado, o que se caracteriza na economia como boom econômico.

Quando esse boom ou "bolha" chega ao seu ápice, o quadro se inverte e o número de agentes muda de posição, com um total de pessimistas maior que otimistas, iniciando assim uma crise financeira. Com isso, há uma repentina desvalorização dos ativos financeiros gerando assim uma onda de pessimismo no mercado, confirmando os motivos que geraram a crise. A amplitude da atual crise é global e já atingiu diversos segmentos a partir do segundo semestre de 2008.

Seus antecedentes históricos são desde o início do ano 2000, quando, na tentativa de estimular o mercado e aquecer a economia, o governo americano decidiu baixar os juros. Com os juros chegando a 1\% ao ano (valor mais baixo nos últimos 50 anos), a população pôde financiar a compra de imóveis e outros bens de consumo que necessitam de crédito financeiro (do governo ou do setor privado). Com estas possibilidades, surge um novo mercado: o mercado de financiamento de imóveis de longo prazo nos Estados Unidos. As imobiliárias percebem a busca por imóveis e começam a apostar em financiamentos de alto risco (subprime), que seria a concessão de empréstimos aos chamados maus pagadores (pessoas com histórico de inadimplência). A nomenclatura Prime e Subprime diz respeito à qualidade 
do crédito, respectivamente, clientes com bom histórico de crédito e clientes com histórico de crédito ruim.

A atual crise é mais complexa, grave e mais duradoura de todas as crises desde o pósguerra. 0 fator detonador da crise foram os empréstimos hipotecários secutirizados para pessoas não qualificadas a honrar com o compromisso. Essa atitude foi tida como uma inovação progressista àqueles cidadãos que desejavam ter sua casa própria (RESENDE, 2008). Devido ao excesso de injeção de dinheiro na economia, houve um aumento na inflação do país e o governo se viu obrigado a elevar os juros para contê-la. Com os juros do país alto, o consumidor tende a comprar menos, porque a prestação de seu financiamento tenderá a subir. Isso reflete na queda da inflação (MANKIW, 2005).

Neste sentido, com o aumento dos juros e também dos financiamentos, o número de pessoas que tiveram maior dificuldade em arcar com os pagamentos aumentou e, conseqüentemente, as inadimplências no pagamento das prestações acordadas junto às instituições financeiras também aumentaram. Estas empresas financiadoras tinham seguradoras ou outras instituições que davam "segurança financeira" às empresas que concediam empréstimos. Quando estas seguradoras foram acionadas pelas empresas financiadoras por causa da solvência e liquidez, o colapso na economia norte-americana aconteceu e tem se refletido em diversas dimensões econômicas e sociais no mundo.

A crise no setor imobiliário alcançou quase que todos os setores da economia mundial e, na área social, não foi diferente. Os desdobramentos na indústria são visíveis, principalmente as empresas que trabalham diretamente com o sistema de financiamento, como as indústrias automotivas. Algumas fecharam suas portas depois de anos reinando no segmento. Montadoras renomadas, como a japonesa Toyota, a americana Ford, a sueca Volvo, entre outras, se viram obrigadas a realizarem demissões coletivas, por conseqüências das fortes baixas nas vendas.

Essas perdas, em diferentes continentes, mostram o nível de globalização em que o sistema financeiro se encontra, bem como a fragilidade que o sistema capitalista oculta. Percebe-se que especulações ou então um simples desajuste na economia de um único país, leva a uma enorme onda de desconfiança por todo o mundo. Para o ganhador do Prêmio Nobel de Economia de 1991, Joseph Stiglitz, pela primeira vez depois da queda do Muro de Berlim outro "velho" o modelo econômico volta a ganhar espaço nos noticiários e corredores do meio acadêmico (GARDELS, 2009).

Alguns fatos são essenciais para entender o que pode ter gerado a crise econômica que o mundo passa. Na verdade é uma sucessão de fatos que tiveram desdobramentos a partir de 2008. Para Barbosa (2008), a crise americana tem como origem o mercado de crédito imobiliário. Já de acordo com Goodhart (2008), a crise é uma combinação do ponto de vista dos Estados Unidos em considerar que os preços dos imóveis subiriam e se estabilizariam com uma política expansionista adotada por muitos anos. Barbosa (2008b) acredita que a crise também é uma questão de equilíbrio entre Eficiência do Mercado e Equidade do Estado.

Agora, mais uma vez, o Estado surge como único porto seguro, o que mostra o absurdo da oposição entre mercado e Estado. 0 Estado tem como função regular e organizar o mercado. Sendo assim, é inviável a proposta dada pelos neoliberais de diminuí-lo, ou até mesmo anulálo (RICUPERO et al, 2008). Para solução do grande problema enfrentado atualmente, a medida adotada é a intervenção do Estado Americano na Economia. Para Barbosa (2008), três são as correntes de tentativa de solução do problema: (i) intervenção em instituições financeiras 
coordenadas pelo FED e pelo FDIC (Federal Deposit Insurance Corporation); (ii) criação de várias linhas de crédito pelo FED para dar liquidez ao sistema financeiro; e, (iii) Plano Pulson dar ao Tesouro Americano recursos para que ele compre papéis "podres". Só quando terminar este momento turbulento será possível analisar a eficiência de tais medidas propostas pelo governo americano.

Segundo Ricupero et al (2008), a crise financeira acarretará em recessões, mudanças de fortunas e atingirá famílias do mundo todo, porém, em breve, a confiança voltará ao mercado e as taxas cambiais se estabilizarão. 0 autor afirma que no final de toda essa turbulência, mesmo deixando cicatrizes nos Estados Unidos, a crise ficará na história, mostrando ao mundo a importância de um governo forte, democrático, dotado de legitimidade política e recursos fiscais.

Embora traçar perspectivas seja mera especulação sobre o futuro econômico, Nakano (2009, p. 09) destaca que o pior da crise financeira ainda está por vir. Para o autor, "há um consenso entre os economistas de que a economia global está entrando na pior recessão desde a Segunda Guerra Mundial". Os efeitos da contração da economia real repercutirão ainda em 2009, agravando ainda mais as condições financeiras como das empresas não financeiras, uma vez que o mercado enfrenta escassez de crédito (um problema grave que muitas empresas de grande porte estão enfrentando). Isso fomenta a discussão, no âmago da Estratégia, sobre questões relativas à sobrevivência, estratégias emergentes, construção de cenários, dentre outros temas.

\section{SETOR DE ENERGIA ELÉTRICA}

O setor de energia elétrica no Brasil possui algumas características após a saída parcial do Estado como gerador e distribuidor deste bem público. A criação da Agência Nacional de Energia Elétrica (ANEEL) como órgão regulador mudou o cenário monopolista anteriormente existente. A partir deste contexto, empresas só podem atuar neste mercado a partir da concessão do governo.

Até 1993, o modelo vigente do setor elétrico brasileiro era o regime tarifário pelo custo, em que os consumidores dos inúmeros estados brasileiros pagavam a mesma tarifa pela energia consumida. Assim, foi nesse ano que a reforma do Setor Elétrico Brasileiro iniciou-se, com a promulgação da Lei no 8.631. Deste modo, contratos de suprimento entre geradores e distribuidores foram criados, o que acabou por extinguir a equalização tarifária até então vigente (CCEE, 2009).

Em 1996, o Projeto de Reestruturação do Setor Elétrico Brasileiro (Projeto RE-SEB) foi implementado, onde as principais necessidades identificadas foram: divisão das empresas de energia elétrica em segmentos de geração, transmissão e distribuição; incentivo à competição nos setores de geração e comercialização; e consolidação da regulação por parte do Estado nos setores tidos como monopólios naturais, tais como os segmentos de distribuição e transmissão de energia elétrica (CCEE, 2009).

O projeto citado teve a coordenação do Ministério de Minas e Energia e foi com base nele que a criação dos seguintes órgãos foi iniciada: a Agência Nacional de Energia Elétrica (ANEEL) e o Operador Nacional do Sistema Elétrico (ONS). Além destes órgãos, foi identificada a necessidade de um ambiente para a realização das transações de compra e venda de energia elétrica, o Mercado Atacadista de Energia Elétrica - MAE (CCEE, 2009).

Dada a edição da Lei $\mathrm{n}^{\circ}$ 10.848, em 2004, o cenário mudou. Um novo marco regulatório do 
setor elétrico foi definido. Assim, o principal instrumento para a contratação de energia pelas distribuidoras passou a ser o leilão e o critério utilizado é o de menor tarifa. Antes de tal lei, a ANEEL ficava responsável pela fixação do limite de preço a ser comprado pelas distribuidoras. Estas podiam adquirir livremente a energia a ser revendida (ONS, 2009).

0 termo concessão diz respeito ao caráter público da distribuição de energia. A regulação não é um fenômeno recente no setor. Desde o século XX, com a aprovação do Código de Águas em 1906, esse fenômeno emergia (RECH, 2004). Mas, recentemente, com a regulação e a criação da ANEEL é que o setor passou por algumas mudanças sistemáticas. Atualmente são quatro tipos de regulação neste setor: regulação da geração, da transmissão, da distribuição e da comercialização (ABD0, 2003). De acordo com Pires (2000), foi o novo contexto da competição na geração e na comercialização da energia elétrica que motivou a inserção de mecanismos de regulação a partir do final da década de 1990.

A Lei $\mathrm{n}^{\mathrm{0}}$ 10.848/2004 teve por objetivo garantir a transparência na compra de energia, proporcionar a competição e a obtenção de melhores preços, além de ratificar o papel estratégico do Ministério de Minas e Energia (MME) como órgão mandatário da União e reforçar a atuação da ANEEL como autarquia sob regime especial com funções de regulação, fiscalização e mediação (ONS, 2009).

Outra contribuição, dada a edição da referida lei, foi a criação: da Empresa de Pesquisa Energética (EPE), instituição responsável pelo planejamento do setor elétrico a longo prazo; do Comitê de Monitoramento do Setor Elétrico (CMSE), instituição que possui a função de avaliar a segurança do suprimento de energia elétrica; e da Câmara de Comercialização de Energia Elétrica (CCEE), instituição que tem por finalidade dar continuidade às atividades do Mercado Atacadista de Energia Elétrica, relativas à comercialização de energia elétrica no sistema interligado (CCEE, 2009). Hoje são 64 concessionárias e 1020 empresas que atuam na geração e comercialização (ANEEL, 2009).

Recentemente, no dia 06 de maio de 2009, a chamada "MP das hidrelétricas" foi aprovada pelos senadores, segundo informações do Senador relator. Tal medida tem por finalidade facilitar o financiamento ao setor de energia elétrica, onde as empresas estatais do setor poderão atuar em empreendimentos de exploração da produção ou transmissão de energia elétrica que estejam presentes no Programa de Aceleração de Crescimento (PAC) ou em programas estratégicos. Estas empresas estatais participarão, assim, do Fundo de Garantia a Empreendimentos de Energia Elétrica - FGEE (SENADO FEDERAL, 2009).

No que diz respeito ao impacto da crise financeira no setor, talvez os reflexos ainda não tenham chegado às empresas. De acordo com o presidente da Associação Brasileira dos Produtores Independentes de Energia Elétrica (Apine), como a energia já está contratada até o ano de 2011, o setor elétrico só perceberá os reflexos da crise em dois anos (RODRIGUES, 2009). Conforme aponta Van Keer (2009), os impactos não são apenas negativos. Um dos principais impactos será a reestruturação do perfil empresarial das firmas neste setor. 0 autor aponta que o principal desafio neste momento de crise é criar um ambiente atraente para os investidores, seja na perspectiva jurídica, ambiental ou de atuação na regulação.

Segundo declarações do chefe responsável pelo Departamento de Infra-Estrutura do Banco Nacional de Desenvolvimento Econômico e Social (BNDES), o setor de energia e de infraestrutura não sofre o impacto imediato da crise, de um modo geral, pelo fato deste segmento ter um pensamento a longo prazo (GANDRA, 2009). Acrescenta ainda que este ano (2009) o referido setor terá mais de $\mathrm{R} \$ 13$ bilhões de reais em recursos desembolsados pelo Banco 
Nacional de Desenvolvimento Econômico e Social (BNDES). 0 chefe citado salienta que as liberações de recursos do BNDES para o setor elétrico têm crescido ao longo dos anos.

Porém, de acordo com o Grupo de Estudos do Setor Elétrico (CASTRO e BRANDÃO, 2008), a desaceleração do PIB influenciará na queda da demanda. Os autores destacam que a taxa de crescimento de consumo já estava decrescendo antes da crise. É afirmado no texto que o setor sofrerá uma queda imediata de consumo, uma vez que o setor industrial é responsável por pouco menos da metade do consumo total de energia. Logo, com a diminuição da produção na indústria, o consumo diminuirá.

Conforme declarações do coordenador do Grupo de Estudos do Setor Elétrico (Gesel) da Universidade Federal do Rio de Janeiro (UFRJ), uma necessidade de ajustes no novo modelo do setor elétrico brasileiro é identificada, dada a crise internacional (GANDRA, 2009). Para ele, tais ajustes no modelo, que completa cinco anos de fundação, têm por base a superação de problemas que estão surgindo no setor, tais como questões relativas ao meio ambiente (problemas na construção de novas usinas hidrelétricas) e ao mercado livre (volatilidade de preços). É afirmado no texto que o atual modelo do setor elétrico apresenta fundamentos muito sólidos. Os leilões realizados são citados como exemplos. Mediante esta realidade, dificilmente a crise financeira internacional afetará drasticamente o cenário brasileiro. 0 mesmo enfatiza que a privatização dos ativos e a utilização de planejamento foram as bases que possibilitaram a consolidação do novo modelo do setor elétrico brasileiro. A superação dos problemas herdados do modelo anterior foi outra conquista para o modelo atual.

\section{METODOLOGIA}

Este item do artigo apresenta o percurso metodológico desta pesquisa. A perspectiva adotada aqui é da Pesquisa Qualitativa, pela possibilidade de aprofundar o conhecimento sobre um determinado fenômeno. A opção pela Pesquisa Qualitativa neste artigo é justificada pelo fato de não existirem trabalhos prévios que abordem a relação da Crise Financeira e as Práticas de Responsabilidade Social em empresas do setor elétrico, o que o torna uma pesquisa do tipo exploratória. 0 método de análise dos dados é Análise de Conteúdo.

Com base no método de definição das empresas que participaram deste estudo, têm-se os seguintes motivos: (i) participação na Carteira do ISE BM\&F-Bovespa para o ano de 2009; (ii) o fato de serem empresas que compõem um setor regulado pelo Estado; (iii) facilidade de respostas aos contatos estabelecidos; e, (iv) pelo pressuposto de que por serem de um setor de fim da cadeia de consumo, o impacto seria diferente.

A técnica utilizada para a coleta dos dados primários foi a entrevista por telefone. Assim, um roteiro de entrevista foi construído e aplicado. Tal ferramenta permitiu dar um maior embasamento às questões que, a priori, não tinham sido consideradas pelo pesquisador no ato de elaboração do instrumento de coleta de dados. A entrevista por telefone foi a abordagem usada. Executivos de quatro empresas do setor de energia elétrica foram entrevistados.

No que se refere ao processo de coleta de dados, foi solicitada, primeiramente, à BM\&FBovespa, a relação dos contatos dos executivos das empresas de energia elétrica que compõem o ISE. Dada esta solicitação, o departamento responsável pelo ISE enviou por email uma lista contendo o nome da empresa, o seu responsável, bem como o seu e-mail de contato. De posse da relação dos responsáveis diretos, um e-mail foi enviado a todos com o objetivo de explicar a pesquisa e, ao mesmo tempo, solicitar o telefone de contato para que o 
agendamento da entrevista fosse realizado. A entrevista por telefone foi marcada em seguida. A opção por esta técnica de entrevista deu-se por questões econômicas da pesquisa e pela dificuldade de recepção dos pesquisadores nas empresas, dada à agenda dos gestores. Um fato verificado com uma das empresas foi que, mesmo por telefone, as entrevistas foram remarcadas inúmeras vezes.

O método de Análise de Conteúdo foi utilizado para a análise dos dados. Por ser um método de busca de informações, tal se enquadra nesta pesquisa dada as suas características epistemológicas, uma vez que tem como principal característica a sistematização de dados para a interpretação de um fenômeno estudado. Além disso, tal método se encaixa tanto para fins exploratórios como para a verificação de hipóteses ou suposições preestabelecidas (VERGARA, 2005).

\section{LIMITAÇÕES METODOLÓGICAS}

O trabalho apresenta duas limitações: (i) a utilização da entrevista por telefone e (ii) problema de agenda dos executivos e tempo para coleta de dados de um grupo maior de empresas. A primeira limitação diz respeito à técnica de coleta de dados. Quando comparada à entrevista pessoal, a entrevista por telefone perde alguns atributos, como, por exemplo, a relação de confiança no pesquisador criada no decorrer de uma entrevista pessoal. Entretanto, tal técnica foi a mais adequada em termos financeiros e de tempo, uma vez que as distâncias geográficas entre as empresas e os pesquisadores dificultaram a realização de entrevistas pessoais.

A segunda limitação surgiu pela dificuldade de agendar entrevistas com os executivos. São profissionais que possuem uma agenda cheia. As ligações foram condicionadas ao tempo disponível dos executivos (que variou entre 20 e 25 minutos).

\section{RESULTADOS}

Os resultados obtidos na pesquisa de campo demonstram como as quatro empresas analisadas foram afetadas pela Crise Financeira no que diz respeito às práticas de Responsabilidade Social. As referidas empresas são de grande porte e representativas nos seus segmentos de atuação. Por negociarem ações na Bolsa de Valores de São Paulo têm capital aberto e um direcionamento de gestão voltado às práticas de Governança Corporativa, o que talvez também contribui para que estas façam parte das 28 empresas que compõem a Carteira do ISE BM\&F-Bovespa para o ano de 2009.

Em geral, percebeu-se a partir da pesquisa de campo que os reflexos da crise financeira não foram negativos para as empresas analisadas. Ainda que o setor seja regulado pelo governo, os dados permitem entender que, embora a Crise Financeira tenha afetado a indústria a situação no setor em análise, quando verificada sob o ponto de vista dos reflexos da crise é a mesma: não se percebeu reflexos negativos nas práticas de responsabilidade social nestas empresas. 0 item seguinte apresenta as especificidades do segmento analisado.

\section{EMPRESAS DO SETOR ELÉTRICO}

As empresas que compuseram este estudo neste setor têm geralmente uma área interna que é responsável pelas questões relacionadas à Responsabilidade Social e à Sustentabilidade. De uma maneira geral, a área de Responsabilidade Social está ligada ou a um departamento de Relações com Investidores ou à área de Comunicação. As práticas de responsabilidade social das quatro empresas são similares. Talvez isso aconteça pelo fato das regulamentações 
governamentais, pelas características do segmento ou pela possibilidade de benefícios fiscais que surgem a partir dos incentivos à cultura (Lei Rouanet). Nas quatro empresas há uma preocupação internacional com sua reputação socialmente responsável, uma vez que também estão listadas no Índice da Dow Jones de Sustentabilidade.

Especificamente, duas categorias direcionam as análises destas práticas de responsabilidade social neste estudo: investimentos externos e política de bem-estar de funcionários. Nas quatro empresas estas ações são construídas por um instituto criado pela empresa que atua diretamente com o público externo em ações sustentáveis.

Uma característica central nestas práticas, quando analisadas na perspectiva dos investimentos externos, é a proximidade da empresa com as comunidades que localizadas próximas às suas áreas de concessão. Assim, os investimentos externos estão geralmente associados à cultura, por causa da Lei Rouanet (que traz benefícios fiscais às empresas); à educação, pelo fato de contribuir para o desenvolvimento de comunidades próximas às áreas de concessão das empresas que atuam na busca da sustentabilidade econômica dos moradores; ou, por outros projetos que aproximem o segmento de atuação da empresa com a realidade do público externo (por exemplo, projetos que explorem características científicas químicas ou físicas da energia elétrica).

No que diz respeito à segunda categoria, política de bem-estar dos funcionários, as empresas têm uma preocupação em alinhar o bem-estar no ambiente de trabalho com a responsabilidade social. Os projetos nestas empresas vão desde a preocupação com a qualidade de vida do funcionário (ginástica laboral, assistência psicológica e planejamento financeiro), ações externas de voluntariado e até o assédio moral (por exemplo, a contratação de uma empresa terceirizada para receber denúncias anônimas que incluem relações de poder de chefe e subordinado, além de denúncias de fraudes internas).

O ponto central do artigo é a relação da crise com as práticas de responsabilidade social empresarial. Assim, o que se verificou nas empresas que participaram deste estudo é que apesar do fenômeno ser mundial e impactar em diversos segmentos da economia, as práticas de responsabilidade social não foram afetadas, de acordo com os gestores das empresas deste setor. Dois são os motivos que podem explicar tal situação: (i) regulamentação dos preços no setor e (ii) o fato do setor estar no final da cadeia de consumo.

O primeiro motivo, a regulamentação de preço, não afetou diretamente o desempenho financeiro da empresa pelo fato de existir um preço mínimo e máximo a ser negociado pelas empresas, e, como a energia é uma utilidade pública, o seu consumo é pouco sensível às situações condicionadas pela crise financeira. 0 segundo motivo deve-se ao fato de o setor de energia elétrica se encontrar no fim da cadeia e não ter sofrido (ainda) impacto. Contudo, isso pode acontecer como um reflexo futuro no desempenho financeiro da empresa (não nas práticas socialmente responsáveis) a partir do momento que acontecer uma redução do consumo na atividade industrial.

Assim, neste segmento, os executivos entrevistados destacam individualmente que embora haja uma política de redução de custos e gastos em suas empresas, as práticas de responsabilidade social não foram afetadas negativamente pela crise. Talvez isso aconteça pelo fato de se perceber que além das características do mercado (regulamentação de preço e final cadeia econômica), as práticas de responsabilidade estão inseridas nos valores e na cultura das empresas. 0 que se percebeu é que pode haver redução de investimentos externos no futuro se a crise permanecer, mas não o cancelamento total destas ações pelas empresas 
do setor de energia elétrica.

\section{ANÁLISE DOS RESULTADOS E CONSIDERAÇÕES FINAIS}

Os dados econômicos de quebra de empresas, a onda de demissões e o pessimismo generalizado sobre o restabelecimento da economia mundial fez consolidar o pressuposto deste trabalho, que fora construído a partir da idéia de que a Crise Financeira traria reflexos negativos às práticas de Responsabilidade Social das empresas. Entretanto, o que se verificou foi que o fenômeno analisado não impactou negativamente o setor de Energia Elétrica. Constatou-se, assim, um entendimento da necessidade das práticas de Responsabilidade Social ou Sustentabilidade nestas empresas (seja em projetos internos de redução de custos/eco-eficiência ou na busca da credibilidade e confiança perante os investidores/transparência).

Outro fator a ser levantado é a questão da regulação. Como a energia é um bem público, regulado pelo Estado e com leilões de compra acontecidos antes da crise, embora os dados mostrem que o setor não sofreu reflexos negativos, talvez isso possa acontecer a partir de 2011 (como apontam alguns especialistas). Já alguns executivos deste setor consideram que estes reflexos negativos não atingirão suas empresas pelo fato da RSE compor seus valores de atuação no mercado.

Basicamente, o que é identificado neste artigo é que as práticas de RSE nas empresas do setor de Energia Elétrica são estruturadas a partir de duas dimensões: (i) Core Business do segmento e (ii) preocupação com o público interno. Os projetos, programas ou ações são realizados com o intuito de alinhá-los com os interesses do setor (educação consciente para consumo de energia, por exemplo) ou para garantir o bem-estar dos funcionários e conscientizá-los tanto na perspectiva social quanto na ambiental.

As análises geradas a partir desta investigação corroboram a perspectiva teórica de que a Responsabilidade Social deve ter uma abordagem sistêmica (SCOTT, 2007), sendo incorporada à Estratégia da empresa - esta importância foi dada pelos próprios executivos. $\mathrm{Na}$ busca da Vantagem Competitiva, o momento que as empresas se encontram perpassa o nível da indústria e das relações entre os grupos e as barreiras de mobilidade na indústria Modelo da Industrial Organization (PORTER, 1979; GHEMAWAT, 2002), e transcende também a visão dos recursos Resource-Based View (BARNEY, 1986).

Assim, na formulação da estratégia, considerar a relação entre stakeholders, sociedade e meio ambiente é inerente àquelas empresas que se destacam no atual contexto econômico e social. Integrar o discurso à cultura destas organizações talvez seja uma das dificuldades na prática da RSE em diferentes organizações. Na busca da Vantagem Competitiva, a reputação de uma empresa pode ser um caminho a ser analisado.

As análises depreendidas deste contexto também podem ser usadas para amenizar um debate antagônico sobre responsabilidade social: Estratégia e Lucro de Empresas versus Perspectiva Filosófica da Responsabilidade Social. Os teóricos mais céticos tendem a criticar as empresas na utilização das práticas de RSE como um caminho de obtenção de lucros, deixando de lado os aspectos centrais da Responsabilidade Social. Entretanto, o que se verificou foi que mesmo com um fenômeno que resultou em impacto de grande magnitude em diversos países, na essência, as práticas de RSE foram mantidas e valorizadas pelas empresas analisadas.

Este resultado, do ponto de vista teórico, é interessante pelo fato de demonstrar que talvez as práticas de RSE estejam sedimentadas nos valores e na cultura organizacional das empresas 
analisadas. Tais resultados vão de encontro às posições teóricas de autores que entendem que na RSE deve-se assumir uma postura sistêmica que inclua públicos interno e externo, sociedade e meio ambiente (SCOTT, 2007; BHATTACHARYYA et al, 2008). Embora não tenha sido o foco deste estudo, talvez seja interessante em trabalhos futuros verificar como a responsabilidade social está sedimentada nos valores, pressupostos e crenças destas empresas e por que razão a crise econômica não afetou as práticas de RSE destas empresas e de empresas de outros setores econômicos (caso essa relação também seja estabelecida).

Estas e outras questões podem ser verificadas em futuras pesquisas que abordem a temática da RSE no contexto de empresas brasileiras. Este trabalho se torna relevante pelo fato de unir dois campos distintos (RSE e Crise Financeira). Embora distintos tais campos têm uma área de interseção: o desempenho da empresa. A principal contribuição deste estudo é apresentar que, embora exista um pressuposto de que as empresas reduziram custos e investimentos por causa da crise, a base da implementação das práticas de RSE nestas empresas tem um direcionamento para uma postura mais abrangente destas práticas, envolvendo públicos interno, externo, sociedade e meio ambiente.

\section{REFERÊNCIAS BIBLIOGRÁFICAS}

ABD0, J. M. M. Avanços na Regulação do Setor Elétrico Brasileiro. In: VII Reunião da Associação Iberoamericana de Entidades Reguladoras de Energia (ARIAE). Oaxaca: VII Reunião da ARIAE, CD-ROM. 2003.

ANEEL. Agência Nacional de Energia Elétrica. Disponível em: http://www.aneel.gov.br. Acesso em 18 abr. 2009.

BARBOSA, I. M. da S. P. Sociedade Civil Brasileira: Ação, Articulação e Mobilização. In: Revista Terceiro Setor. V. 1, no1, 2007 (pp. 34-38).

BARBOSA, F. de H. A Crise Financeira de 2007/2008 (?). In: Conjuntura Econômica. V. 62, noㅜ 10, out, 2008, p. 10.

As lições políticas da crise financeira. In: Conjuntura Econômica. V. 62, no 12, dez, 2008b, p. 16.

BHATTACHARYYA, S. S., SAHAY, A., ARORA, A. P. e CHATUVERDI, A. A toolkit for designing firm level strategic corporate social responsibility (CSR) initiatives. In: Social Responsibility Journal. V. 4, no 3, 2008 (pp. 265-282).

BOVESPA. Bolsa de Valores de São Paulo. Disponível em: www.bovespa.com.br. Acesso em: 18 mar. 2009.

CASTRO, N. J. de e BRANDÃO, R. A crise econômico-financeira e os Impactos no Setor Elétrico Brasileiro. Disponível em: http://www.nuca.ie.ufrj.br/gesel/. Acesso em 17 abr. 2009.

CCEE. Câmara de Comercialização de Energia Elétrica. Disponível em: http://www.ccee.org.br/cceeinterdsm/v/index.jsp?vgnextoid=96a0a5c1de88a010VgnVCM1 00000aa01a8c0RCRD. Acesso em 07 mai. 2009.

GANDRA, A. Novo modelo do setor elétrico requer ajustes, recomenda professor. Disponível em: $\quad$ http://www.agenciabrasil.gov.br/noticias $\quad$ /2009/03/18/materia.2009-0318.6593473542/view. Acesso em 06 mai. 2009. 
. Setor de energia elétrica terá este ano R \$ 13 bilhões em recursos do BNDES. Disponível em: $\quad$ http://www.agenciabrasil.gov.br/noticias/2009/03/23/ materia.2009-0323.8910443760/view. Acesso em 07 mai. 2009.

GARDELS, N. A crise de Wall Street equivale à queda do Muro de Berlim. Tradução de Marco Aurélio Weissheimer. Disponível em: http://www.sinprodf.org.br/blog/?p=14. Acesso em 12 abr 2009.

GHEMAWAT, P. Competition and Business Strategy in Historical Perspective. In: Business Historical Review. V. 36, (Spring), 2002, p. 37-74.

GO0DHART, C. A crise financeira global. In: Conjuntura Econômica. V. 62, no 11, nov, 2008, p. 10-13.

HECK, S. Liquidez: Empoçamento? In: BACHA, E. L e GOLDFAJN, I. (Orgs). Como Reagir à Crise? Políticas Econômicas para o Brasil. 1a versão. Rio de Janeiro: IEP/CdG, 2008. p. 5456.

HESLIN, P. A. e OCHOA, J. G. Understanding and developing strategic corporate social responsibility. In: Organizational Dynamics. 2008, Vol. 37 Issue 2, p125-144, 20p.

MANKIW, N. G.. Introdução a Economia. Tradução da 3ª Edição, Editora Thomson, 2005, cap. 34.

MUJIH, E. Implementing Corporate Social Responsibility: Punishment or Compliance? In: Social Responsibility Journal. Vol. 3, n , 2007 (p. 79-85).

ONS. Operador Nacional do Sistema Elétrico. Disponível em: http://www.ons.org.br/institucional/modelo_setorial.aspx. Acesso em 06 mai. 2009.

PETERS, J. Social responsibility is free? In: The TQM Magazine. Vol. 9, no 1 . MCB University Press. 1997 (pp. 4-5).

PIRES, J. C. L. Desafios da Reestruturação do Setor Elétrico Brasileiro. Texto para Discussão 76. BNDES. Disponível em: http://www.bndes.gov.br/conhecimento/td/Td-76.pdf. Acesso em 17 abr. 2008.

PORTER, M. E. How competitive forces shape strategy. In: Havard Business Review. V. 57, no 2, 1979, p. 137-145.

RECH, H. Regulação dos Serviços Públicos de Energia Elétrica. 2004. 125f. Dissertação de conclusão de curso (mestrado) - Escola Politécnica da Universidade de São Paulo, São Paulo, 2004.

REINERT, J. N.. Desemprego: causas, conseqüências e possíveis soluções. Revista de Ciências da Administração, Florianópolis, v. 3, n. 5, p. 45-48, 2001.

RICUPERO, R; BRESSER-PEREIRA, L. C.; OCAMPO, J. A. e NASSIF, L. A crise internacional e seu impacto no Brasil. In: Estudos Avançados. V. 22, no 64, 2008, p.185-214.

RODRIGUES, L. Crise financeira pode impactar setor de energia em dois anos, diz associação. Folha Online. Disponível em: http://www1.folha.uol.com.br/folha/dinheiro/ult91u448104.shtml. Acesso em 17 abr. 2009. 
RUMELT, R. P., SCHENDEL, D. e TEECE, D. J. Strategic Management and Economics. In: Strategic Management Journal. V. 12, 1991, p. 05-29.

NAKANO, Y. 0 pior ainda está por vir. In: Conjuntura Econômica. V. 63, no 01, jan, 2009, p. 0911.

SANGLARD, G. Filantropia e assistencialismo no Brasil. Hist. cienc. saude-Manguinhos [online]. 2003, v. 10, n. 3, pp. 1095-1098. ISSN 0104-5970.

SCOTT, S. Corporate Social Responsibility and the Fetter of Profitability. In: Social Responsibility Journal. Vol. 3, no 4, 2007 (p. 31-39).

SENADO FEDERAL. Aprovada MP que facilita financiamento ao setor de energia elétrica. Disponível em: http://www.senado.gov.br/agencia/verNoticia.aspx?codNoticia=90718\&codAplicativo=2. Acesso em 07 mai. 2009.

TEECE, D. J., PISANO, G. e SHUEN, A. Dynamic Capabilities and Strategic Management. In: Strategic Management Journal, Vol. 18, № 7 (Aug.), 1997, p. 509-533.

TENORIO, F. G. (org). Responsabilidade Social Empresarial: Teoria e Prática. Coleção FGV Prática. Rio de Janeiro: Editora FGV, 2004.

VAN KEER, H. F. A crise financeira e o setor elétrico, uma visão empresarial. Disponível em: http://indexet.gazetamercantil.com.br/arquivo/2009/03/17/400/A-crisefinanceira- eo-setor-eletrico,-uma-visao-empresarial.html. Acesso em 17 abr. 2009.

VERGARA, S. C. Métodos de Pesquisa em Administração. São Paulo: Atlas, 2005.

WILLIANSON, O. E. Stratezing, Economizing and Economic Organization. In: Strategic Management Journal. V. 12, Special Issue - Fundamental Research Issues in Strategy and Economics (Winter), 1991, p. 75-94).

1 Todas as informações apresentadas neste item do artigo foram construídas com base na interpretação das informações coletadas no site www.bovespa.com.br a partir das definições apresentadas pela BM\&F-Bovespa. 